\title{
Da tutela à Autonomia: Narrativas e Construções do Cotidiano em uma Residência Terapêutica ${ }^{1}$
}

From the guardianship to autonomy: Narratives and constructions of daily life

in a residential service
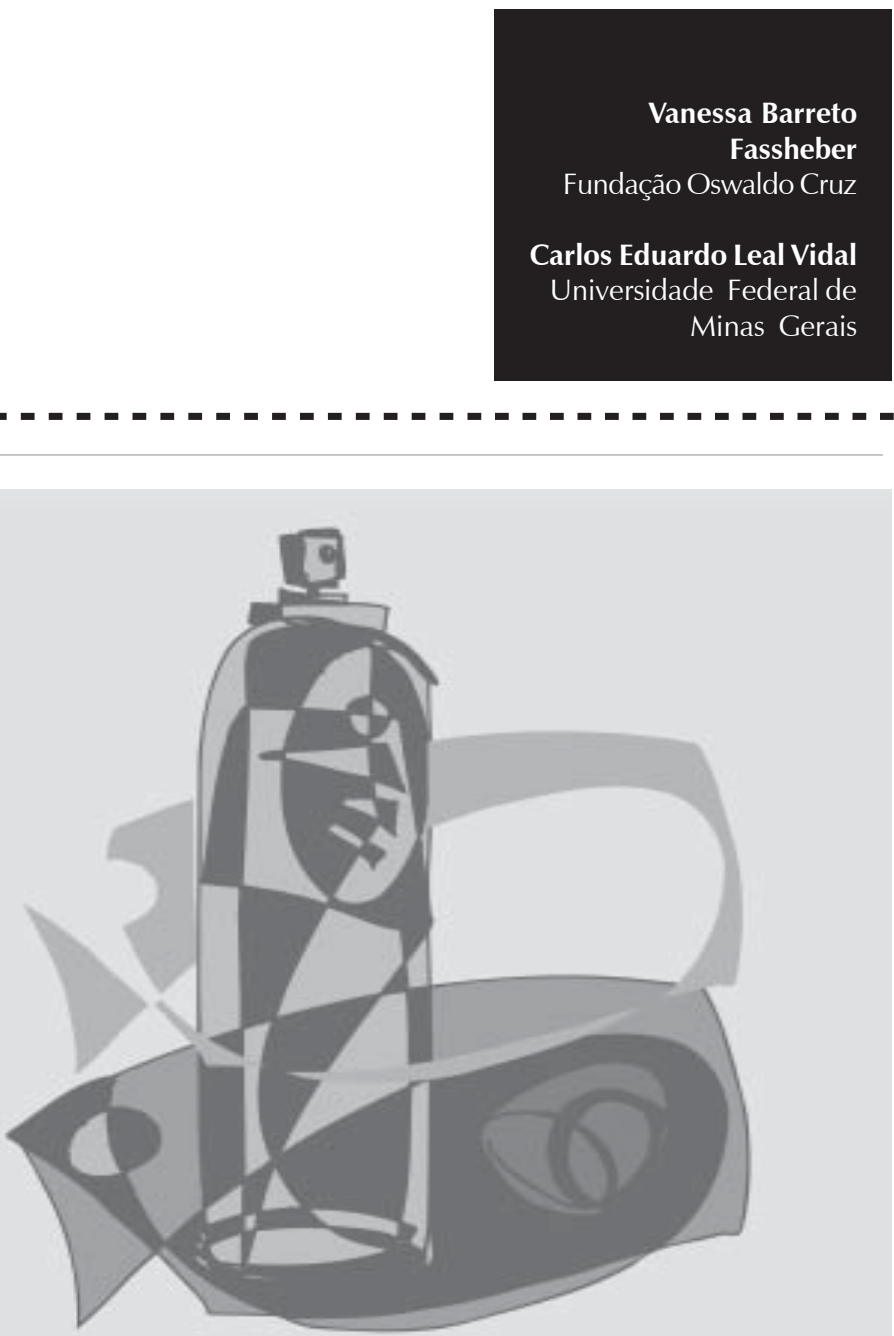

Este artigo é baseado na monografia de Vanessa Barreto Fassheber, sob a orientação de Carlos Eduardo Leal Vidal, apresentada ao Curso de Graduação em Psicologia da Universidade Federal de Juiz de Fora, em janeiro de 2005. 


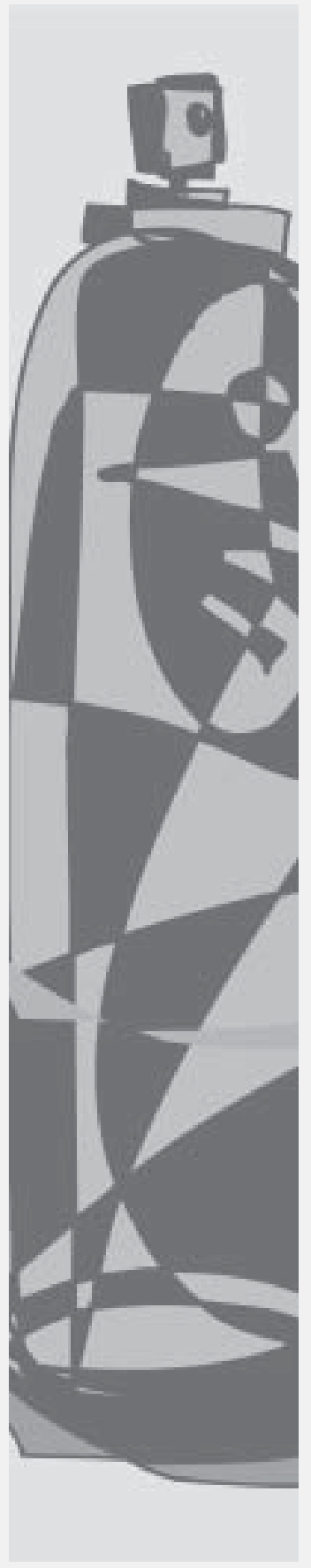

Resumo: A reforma psiquiátrica emerge como um movimento social que propõe uma outra relação entre a loucura e a sociedade. Novos dispositivos assistenciais são criados, tais como a residência terapêutica. Esse serviço atende pacientes crônicos com histórico de internações psiquiátricas. A partir do final da década de 1990, são iniciadas experiências de montagem desses serviços em diversas partes do nosso país. Contudo, é somente no ano 2000 que o Município de Barbacena, Minas Gerais, ganha a sua primeira residência, constituída por seis moradoras. Este artigo evidencia os processos individuais de reconstrução da identidade das moradoras da referida casa. Observa-se que, além de tal processo, as moradoras passam ainda por uma complexa elaboração subjetiva do novo espaço de moradia e pela construção de uma nova rede social. Os métodos de pesquisa adotados foram a observação participante e a coleta de narrativas e histórias de vida dos usuários integrantes da primeira residência terapêutica de Barbacena.

Palavras-chave: reforma psiquiátrica, residência terapêutica, reconstrução da identidade, histórias de vida.

Abstract: The process of psychiatric reform is a social movement that proposes a new relationship between society and insanity. It's a construction of a net of services, as the mental health residential service. This service attends people with chronic mental disease. Since the end of the 1990's, some experiences in mental health residential services are set up in many places of our country. However, the first residential service in the city of Barbacena, Minas Gerais, was developed only in 2000, with 06 patients. This article shows the individual process of identity reconstruction for each resident who lives in the first Barbacena's residential service and identifies the subjective construction of the space of the residence and the building of a new social net. The methods used in this research were the participant observation and the collection of narratives and life histories of the first Barbacena's residential service dwellers.

Key words: psychiatric reform, residential service, identity reconstruction, life stories. 


\section{Introdução: novas práticas e saberes para a saúde mental}

Em todo o mundo, a reforma psiquiátrica foi concebida como um processo que envolve duas dimensões: a diminuição de leitos nos hospitais psiquiátricos e o desenvolvimento de um serviço de saúde mental comunitário adequado, incluindo a infra-estrutura residencial e de serviços e o atendimento dos pacientes por equipes multidisciplinares (Bandeira; Gelina; Lesage, 1998). Na segunda dimensão desse processo, situam-se os serviços residenciais terapêuticos (também conhecidos por residências terapêuticas), modalidade substitutiva de atendimento que se destina a abrigar pacientes egressos de longas internações em instituições psiquiátricas.

O Ministério da Saúde define os serviços residenciais terapêuticos como "moradias ou casas inseridas, preferencialmente na comunidade, destinadas a cuidar dos portadores de transtornos mentais, egressos de internações psiquiátricas de longa permanência, que não possuam suporte social e laços familiares e que viabilizem sua inserção social" (Ministério da Saúde, 2004).

Tais serviços possuem, como premissa básica, a manutenção do sujeito em sua comunidade, de modo que não ocorram perdas de suas relações sociais e referências subjetivas. Destaca-se, em especial, por ser um dispositivo facilitador no processo de reabilitação do paciente que deixa o hospital após uma internação prolongada. Inseridos em uma residência, os pacientes reconstroem, nesse novo espaço, sua identidade, e tecem diariamente uma nova rede social. Dessa forma, pode-se conceber esse serviço como uma ponte entre o hospital e a comunidade. Além de deslocar a assistência do hospital para o território, permite também a criação de uma nova relação entre a loucura e a sociedade.
No Brasil, atualmente, existem mais de trezentas RTs distribuídas em catorze Estados, abrigando mais de mil e quinhentas pessoas. Apesar de esse número parecer expressivo, pode-se dizer que esses serviços ainda estão em fase embrionária, representando apenas $11 \%$ do total previsto. Estima-se que, no Brasil, ainda existam cerca de catorze mil pacientes (de um total de quarenta e quatro mil leitos psiquiátricos) que poderiam ser desospitalizados e residir na comunidade (Furtado, 2005a, 2005b).

A cidade de Barbacena tem grande importância nesse cenário, tendo sido, durante muitos anos, responsável pela demanda psiquiátrica de Minas Gerais; constituiu-se, por muitos anos, em uma referência no atendimento hospitalar. Após denúncias a respeito da falência terapêutica e estrutural, e paralelamente ao processo de reforma psiquiátrica, o Município passa por uma série de mudanças que culminam na reestruturação do seu sistema de saúde mental através da criação de uma rede de serviços substitutivos de cunho territorial, incluindo as residências terapêuticas (RTs), onde residem atualmente os pacientes que foram desospitalizados.

Após anos de reclusão, a subjetividade dos pacientes passa a ser construída nos moldes dotados pela instituição. Com a mudança para a RT, tais sujeitos são defrontados com uma outra realidade, e precisam reelaborar todo o seu universo de significados. A forma pelo qual cada morador reorganizará sua identidade é bastante peculiar e constitui o foco deste estudo, que foi realizado no ano 2004, na primeira residência terapêutica do Município de Barbacena.

Breve histórico sobre a reforma psiquiátrica Os primeiros movimentos da reforma eclodem, após a II Guerra Mundial, em países como Inglaterra, França e Estados Unidos. Cada país desenvolveu suas próprias tentativas de reformulação da assistência psiquiátrica 
seguindo propostas diferentes, embora todas tivessem, em comum, o objetivo de reorganizar a assistência à doença mental. São elas: comunidade terapêutica (Inglaterra), psicoterapia institucional e psiquiatria de setor (França) e psiquiatria comunitária ou preventiva (EUA).

Será somente a partir dos anos 60 e 70, contudo, que surgirão movimentos capazes de levantar os primeiros debates e questionamentos acerca de uma efetiva ruptura com os saberes e práticas psiquiátricas. Busca-se uma verdadeira desconstrução do arcabouço teórico e prático da psiquiatria, com o intuito de construir novas possibilidades para o campo da reforma. Nesse contexto, destacase a psiquiatria democrática italiana.

O psiquiatra italiano Franco Basagalia iniciou uma bem sucedida atuação nas cidades de Gorizia e Trieste nas décadas citadas, onde promoveu uma grande mudança institucional no interior do próprio hospital. Basaglia "transformou o hospital, num primeiro momento, em uma comunidade terapêutica, e depois, consciente das limitações, propôs devolver o doente mental à sociedade, desarticulando a instituição, o manicômio" (Desviat, 1999, p. 42).

A reforma psiquiátrica brasileira é fortemente influenciada pela experiência italiana. É um movimento recente, e suas primeiras manifestações ocorreram a partir da década de 80 (Birman, 1992). Um importante marco desse processo foi a constituição do Movimento de Trabalhadores em Saúde Mental (MTSM), que teve atuação bastante ampla e inseriu-se em diversos meios, como universidades, sindicatos e conselhos profissionais. Esse movimento surgiu a partir de uma série de denúncias de profissionais com relação às péssimas condições a que eram submetidos os pacientes nos hospitais, e seus principais objetivos eram lutar pelos seus direitos profissionais e por mudanças na assistência psiquiátrica (Amarante, 1995).
Diversas conferências e encontros são realizados, com o objetivo de discutir os rumos da assistência brasileira para o setor. Nesse cenário, destaca-se a I Conferência Nacional de Saúde Mental e o II Congresso Nacional do MTSM, ambos em 1987. Os eventos reúnem lideranças públicas, usuários, familiares, técnicos e demais atores envolvidos no processo.

No ano 1989, é apresentado, ao Congresso Nacional, o Projeto de Lei no 3657/89, de autoria do Deputado Paulo Delgado (PT - MG), que traçava os princípios norteadores da reestruturação dos cuidados psiquiátricos no País. Esse projeto previa a extinção gradativa dos hospitais psiquiátricos e a regulamentação dos direitos das pessoas portadoras de transtornos mentais. Além da extinção dos manicômios, o projeto proibia, ainda, a construção de qualquer hospital psiquiátrico em todo o território nacional bem como o financiamento estatal de leitos em hospitais privados. O projeto passou por várias discussões e mudanças, culminando na promulgação da Lei Federal no 10216, de 6 de abril de 2001, que dispõe sobre a proteção e os direitos das pessoas portadoras de transtornos mentais e redireciona o modelo assistencial em saúde mental. Nesse momento, o Brasil efetivava a reforma psiquiátrica em seu território, inclusive na esfera jurídica.

\section{Notas sobre a reforma psiquiátrica em Barbacena - Minas Gerais}

Barbacena é um Município do Estado de Minas Gerais conhecido em todo o Brasil e no exterior como a "Cidade dos Loucos", devido ao grande número de hospitais psiquiátricos que havia na cidade. O primeiro, denominado o Hospital Colônia, foi criado no ano 1903, sendo hoje conhecido como Centro Hospitalar Psiquiátrico de Barbacena (CHPB). "transformou o hospital, num primeiro momento, em uma comunidade terapêutica, e depois, consciente das limitações, propôs devolver o doente mental à sociedade, desarticulando a instituição, o manicômio"

Desviat 
Os doentes chegavam em trens lotados, que vinham de cidades e até de Estados vizinhos. No hospital, os pacientes viviam amontoados, nus, e dormiam no chão forrado de folhas. Já em 1905, surgem reclamações sobre as condições internas do hospício. Tornando-se referência em Minas Gerais, o hospital recebia, a cada dia, mais e mais pacientes, chegando a abrigar mais de quatro mil pacientes em alguns períodos de sua história, o que resultou numa assistência precária e em elevado número de mortes. A partir dessas condições, começam a surgir críticas e denúncias ao hospital.

No ano 1961, uma emissora de TV exibiu um filme apontando a grave situação dos internos do Hospital Colônia de Barbacena. Nesse mesmo ano, uma série de reportagens enfatiza as denúncias exibidas no filme (Magro, 1992). Em julho de 1979, Franco Basaglia visita o Brasil e conhece o Hospital; demonstra perplexidade com o quadro da instituição e compara-a a um campo de concentração nazista (Delgado, 1994). Nesse mesmo ano, o jornalista Hiram Firmino publica um livro, intitulado Nos Porões da Loucura, no qual destaca a precariedade do atendimento prestado aos mil, trezentos e sessenta internos, que contavam somente com seis médicos (Firmino, 1982).

A partir da visita de Basaglia, Barbacena ganha projeção internacional. Algumas medidas demonstram a tendência do Município de reformular seu modelo assistencial, tais como a criação de uma unidade específica para atendimentos a pacientes agudos, um ambulatório e diversos módulos residenciais dentro do próprio CHPB.

Uma importante iniciativa que demonstra a introdução de uma nova lógica assistencial e cultural no Município é a criação do Museu da Loucura, no ano 1996. O Museu conta a história do velho manicômio através de peças que representam o tratamento destinado aos internos em um passado não tão distante.
Podem ser vistos aparelhos de eletrochoque, algemas, correntes e instrumentos para lobotomia, além de um vasto acervo de documentos e fotos.

No campo político-assistencial, o Município adotou uma estratégia que se revelou de grande valia para uma efetiva transformação dos cuidados em saúde mental. No ano 2001, é realizado um mapeamento dos usuários de todo o sistema psiquiátrico da cidade. Esse levantamento, de caráter quantitativo, permitiu conhecer a clientela hospitalar no que diz respeito à procedência, idade, tempo de internação, situação previdenciária e vínculo familiar. Além disso, buscou-se mapear os serviços já existentes no Município. Os dados obtidos apontaram um sistema constituído basicamente por assistência hospitalar e uma numerosa população asilar nos cinco hospitais psiquiátricos existentes na cidade (Barbacena, 2004).

Após a realização de tal diagnóstico institucional, foi elaborado um projeto que visava à construção de um novo modelo assistencial. Baseado nos pressupostos e diretrizes da reforma, o projeto orientou-se para a construção de uma rede substituta que fosse efetiva e resolutiva para o hospital psiquiátrico.

O processo de reforma psiquiátrica no Município foi deflagrado a partir da implantação do CAPS Municipal em 2002, que passou a atuar como porta de entrada reguladora do sistema, função essa atribuída anteriormente ao CHPB. Além do CAPS, diversos outros serviços substitutos foram implantados no Município, o que possibilitou um trabalho em rede.

Constituída a rede de serviços substitutos em saúde mental do Município, torna-se possível pensar em estratégias para retirar pacientes dos hospitais psiquiátricos e tratá-los nos serviços extra-hospitalares. Nesse sentido, foi inaugurado, em 2000, o primeiro serviço
Hospital Dia - Alcoole Drogas, Ambulatório do CHPB e Centro de Convivência. 
residencial terapêutico da cidade, o que se constituiu, portanto, em um projeto piloto. Hoje, já são vinte e um serviços como esse em todo o Município.

\section{Aspectos metodológicos}

O presente estudo foi realizado no primeiro serviço residencial terapêutico implantado na cidade de Barbacena. A referida RT foi escolhida por se constituir, quando da sua criação, em um projeto- piloto e tornar-se uma referência dentro do processo da reforma psiquiátrica no Município. Por ser a primeira, essa casa recebia maior atenção da equipe (composta por psiquiatra, assistente social, psicóloga e técnicos de enfermagem), sendo os atendimentos realizados na própria residência, o que gerou um excesso de cuidados com as moradoras, dentro de uma lógica assistencialista. Nesse período inicial, houve uma grande preocupação da equipe com a possibilidade de erros na condução do processo, o que poderia levar à paralisação do projeto. Passado esse primeiro momento, redefiniu-se o papel da casa como um local de (re)construção da autonomia e da autoestima (Vidal, Gontijo \& Bandeira, 2006).

Definido o campo onde o trabalho seria desenvolvido, restou selecionar a abordagem metodológica bem como os instrumentos e o referencial teórico. Sendo assim, optou-se por adotar a abordagem qualitativa, por saber que esta se ocupa de um nível de realidade que não pode ser quantificado. Desse modo, tornase possível descobrir o que é significativo na vida dos sujeitos da amostra, suas percepções e interpretações do mundo. A pesquisa qualitativa "(...) trabalha com o universo de significados, motivos, aspirações, crenças, valores e atitudes, o que corresponde a um espaço mais profundo das relações, dos processos e dos fenômenos que não podem ser reduzidos à operacionalização de variáveis" (Minayo, 1994, p. 22).

Foi adotada a entrevista como instrumento pelo reconhecimento de que a análise do material coletado pode fornecer-nos ricas informações a respeito do sujeito que é submetido a ela. Além da entrevista, foi realizada também observação participante com o intuito de "(...) captar uma variedade de situações ou fenômenos que não são obtidos por meio de perguntas (...)" (op. cit., 1994, p. 59).

Foram definidos três pontos sobre os quais se deteriam as observações: hábitos do cotidiano e grau de autonomia, relação com os demais moradores e relação com a sociedade. Esses critérios foram estabelecidos considerando-se que o comportamento social e o desempenho das habilidades de vida cotidiana são as áreas mais afetadas em pacientes com vários anos de internação, além de um dos principais objetivos dos programas de reinserção social ser o desenvolvimento de habilidades que resultem em maior grau de autonomia em diversas áreas da vida cotidiana. Trabalhos realizados em outros países têm indicado que os pacientes desospitalizados apresentam melhora nas habilidades de vida diária, na interação social, no nível geral de funcionamento e na qualidade de vida (Rothbard et al., 1999; Leff; Trieman, 2000; Barbato et al., 2004).

Sendo assim, buscou-se compreender a reconstrução de identidade e do novo dispositivo assistencial a partir das falas dos próprios atores sociais, isto é, dos moradores. A maneira pela qual as histórias de vida são reorganizadas e como novas possibilidades são construídas a partir da interação do indivíduo com o seu meio social terá papel central na análise das narrativas.

Parte-se de uma perspectiva construcionista social, que concebe ser a realidade construída pelo sujeito no contexto de sua ação social. Dito de outra forma, a realidade existe a partir do modo pelo qual o sujeito a acessa. $\mathrm{O}$ indivíduo atribui sentidos aos elementos que estão no seu espaço perceptivo. Spink (2000) destaca que:
"(...) trabalha com o universo de significados, motivos, aspirações, crenças, valores e atitudes, o que corresponde a um espaço mais profundo das relações, dos processos e dos fenômenos que não podem ser reduzidos à operacionalização de varióveis"

Minayo 
O sentido é uma construção social, um empreendimento coletivo, mais precisamente, interativo, por meio do qual as pessoas - na dinâmica das relações sociais historicamente datadas e culturalmente localizadas - constroem os termos a partir dos quais compreendem e lidam com as situações e fenômenos a sua volta (p. 41).

Desse modo, as práticas discursivas constituem o foco principal da análise através da perspectiva construcionista, uma vez que englobam seleções, escolhas, ações e contextos que representam um caminho de compreensão para a produção de sentidos no cotidiano. Os construcionistas sociais consideram a narrativa como princípio organizador da ação humana, através das descrições e explicações que as pessoas constroem pela linguagem.

\section{Construindo um novo espaço de moradia}

A criação de uma rede de serviços alternativos ao hospital foi de suma importância para que o município de Barbacena pudesse seguir os preceitos da reforma psiquiátrica. Sem os serviços substitutivos, torna-se inviável a retirada de pacientes das instituições psiquiátricas para o tratamento no espaço extrahospitalar. A desinstitucionalização não pode acarretar a desassistência aos portadores de sofrimentos psíquicos, mas sim, possibilidades mais humanas de tratamento.

Através das narrativas das seis moradoras da primeira residência terapêutica de Barbacena e de observações participantes realizadas na casa, tornou-se possível analisar e compreender o processo de reconstrução de identidade e de subjetividade nesse novo espaço de moradia.

A análise do material obtido evidencia que os moradores passam por um complexo processo de adaptação do novo espaço, e, por isso, atribuem sentidos aos elementos que estão em seu espaço perceptivo através de um processo singular (Spink, 2000). Além de adaptar-se ao novo espaço da casa, tais sujeitos se deparam, ainda, com todo o território onde a mesma se insere.

Para facilitar a compreensão da singularidade do processo de reconstrução de identidade e apropriação do novo espaço de moradia, as narrativas serão apresentadas por entrevistas realizadas. Destaca-se que todos os nomes são fictícios, e foram escolhidos pelas próprias entrevistadas.

Ana Paula, 61 anos

Ana Paula destaca-se por sua desinibição para falar com pessoas fora de seu convívio social, já tendo, inclusive, concedido entrevistas para jornais e emissoras de TV. Demonstra pleno conhecimento de seus direitos e de assuntos ligados à saúde mental. Assume função de liderança na casa, e comumente monopoliza a atenção dos que estão a sua volta.

Relata que seus "problemas" começaram a partir da morte do pai, o que a levou a ser internada aos quarenta e três anos. A moradora encara o ingresso no hospital como uma "salvação", referindo-se à instituição hospitalar de forma carinhosa. A internação passa a ser concebida em uma lógica singular, onde cada sujeito atribui um significado diferente para a sua institucionalização.

O hospital passa a ser um constituinte significativo da identidade do sujeito, especialmente para aqueles que lá permaneceram por muito tempo. Nas instituições totais, é bastante comum que o indivíduo estabeleça relações amistosas com funcionários para obter favores ou algum auxílio financeiro. Goffman (1961) dá, a esse fenômeno, o nome de "sistema de privilégios". A possibilidade de sair do manicômio e passar a residir em uma casa representou um 
momento de medo e apreensão. O comportamento ativo de Ana Paula certamente contribuiu para sua rápida adaptação ao novo lar. Logo assumiu as tarefas da casa, passou a circular pela vizinhança e inseriu-se em sua nova rede social, construindo novas possibilidades para a sua vida até então inexistentes no espaço institucional. Em suas próprias palavras: "Agora eu tô numa casa, graças a Deus... aqui nós comemos o que nós queremos, tem tudo que nós gostaríamos de ter, cada uma tem o seu quarto, tem suas coisas, cada um tem sua vida."

A conquista da autonomia é o principal objetivo do projeto de residências terapêuticas. Ana Paula conquistou um novo espaço para a sua individualidade, onde é permitido ao sujeito ter vontade própria, onde o seu desejo é respeitado. A entrada na residência terapêutica representa, para ela, apenas o primeiro passo em um longo, mas recompensador processo de reconstrução da própria identidade.

\section{Cristina, 41 anos}

Cristina possui um defeito físico que Ihe dificulta andar, e, por isso, passa boa parte do tempo sentada ou deitada em sua cama. Recebe auxílio de outras moradoras para ir à rua ou solicita que as mesmas façam compras pra ela. Quando se sente bem, auxilia na preparação do almoço, picando legumes.

Relata ter sido encontrada nas ruas de Belo Horizonte aos dois anos de idade, por ter sido rejeitada pela família devido ao seu problema físico. A fala de Cristina remete constantemente a sua "falta de lugar", por ter ficado em diversas instituições pelo fato de sua família não acolhê-la. A mágoa resultante desse abandono é o motivo que a teria levado ao hospital psiquiátrico.

A permanência na instituição psiquiátrica assume significados diversos, variando para cada sujeito. Cristina elaborou-a de forma negativa, destacando que sua institucionalização a tornou uma pessoa agressiva. Apesar de desejar sair do hospital, os primeiros contatos com o projeto de residências terapêuticas não foram bem aceitos. A moradora temia ser "jogada na rua". Sobre a angústia da possibilidade de sair do espaço de tutela, Goffman (1961) aponta:

A angústia do internado quanto à liberação parece apresentar-se, muitas vezes, sob a forma de uma pergunta que apresenta a si mesmo e aos outros: 'será que posso me sair bem lá fora? Essa pergunta abrange toda a vida civil como algo a respeito da qual tem concepções e preocupações (Goffman, 1961, pp. 66-67).

A casa permite ao sujeito engajar-se na construção de projetos individuais. O desejo de recuperar-se é, para Cristina, sua referência neste momento. As colegas da casa atuam como uma rede de apoio que tem possibilitado à moradora a conquista de um lugar que, até então, esta não possuía, bem como a construção e o estabelecimento de novos vínculos afetivos.

Inês, 60 anos

Assim como Ana Paula, possui grande facilidade de falar em público, participando de eventos sociais nos quais é convidada a falar sobre sua experiência na casa. Circula com grande desenvoltura por locais públicos, recebendo muitos convites para participar de eventos da área de saúde mental, em que, de modo geral, é convidada a falar sobre sua história.

Muito religiosa, dedica grande parte do seu tempo às orações. Assiste freqüentemente o canal de TV que exibe missas e vai sempre à Igreja, onde participa ativamente como membro de algumas congregações. Voltou a estudar para concluir o $2^{\mathrm{o}}$ grau, mas parou temporariamente. Já vislumbra a possibilidade de alugar um imóvel para morar sozinha.

Foi internada em um hospital psiquiátrico aos vinte e três anos devido a uma dor na perna. 
Como nenhum médico conseguiu solucionar o problema, este foi considerado psicológico. A entrada na instituição psiquiátrica é explicada, por Inês, como a tentativa da família de curá-la de seus problemas. Diz que por qualquer motivo se internava, o que serve para a moradora como justificativa para seu encaminhamento ao hospital.

No caso de Inês, o padrão definido para decidir ou não pela internação era a dor na perna: se a dor voltasse e persistisse, então era hora de se internar. A adaptação ao hospital foi difícil, mas facilitada pelo bom relacionamento que manteve com os funcionários da instituição, por isso, possuía algumas regalias, como a possibilidade de fazer alguns trabalhos e obter retorno financeiro.

Os privilégios concedidos pela instituição à paciente foram fatores determinantes para que esta se adaptasse à institucionalização e desenvolvesse uma relação afetiva com o hospital. Tais laços são mantidos mesmo após a saída do espaço hospitalar e a inserção em um novo cenário, influenciando, muitas vezes, o modo pelo qual o morador irá lidar com seu novo espaço de moradia.

Cada morador vivencia a transição para a residência terapêutica de forma particular, produzindo uma gama de novos significados em sua relação com o novo lar. Enquanto alguns moradores se sentem apreensivos com a mudança, Inês a concebeu como uma dádiva de Deus, como se Ele tivesse finalmente atendido suas preces.

Inês adaptou-se rapidamente a sua nova casa. Encontrou, na residência, um local para reconstruir sua identidade e vivenciar novas experiências: "Aqui na casa eu tenho os meus dias de ir pra cozinha, gosto de com carinho fazer, de preparar o almoço (...) Hoje estou livre. Pra mim a psiquiatria tá se acabando e eu quero, nas minhas orações, não deixo de rezar, que seja bom, que se aproveite a liberdade e eu mais ainda."
Ao dizer que a "psiquiatria está se acabando", Inês refere-se ao modelo de tratamento psiquiátrico vigente no manicômio. Esse "fim da psiquiatria" nada mais é do que a reforma psiquiátrica, que permite ao sujeito a possibilidade de tratar-se dentro de seu próprio território. A residência emerge como espaço potencializador de trocas e relações sociais, permitindo que o indivíduo recupere o seu poder contratual.

Inês relata, com muito entusiasmo, suas viagens e participações em eventos. Recordase, em especial, do encontro que teve com o Ministro da Saúde em um dos eventos de que foi convidada a participar.A cadeira marcada com seu nome, os autógrafos distribuídos e a homenagem na placa são apenas algumas das formas pelas quais Inês pôde reafirmar sua identidade. A residência proporcionou a essa moradora a possibilidade de construir um projeto de vida particular, no qual é possível reconhecer-se como indivíduo, como cidadã. Sobre o hospital? Inês responde enfaticamente: "Hospital? O hospital pra mim morreu. Assunto morto. Nem me lembro mais. Acabou."

Carla, 48 anos

Carla foi a última moradora a chegar à residência, proveniente de um hospital psiquiátrico que foi fechado pelo governo em 2003. Possui um bom grau de autonomia e circula pela cidade sem auxílio de qualquer pessoa. Seu namorado, que também era interno no hospital em que estava, acabou sendo transferido para outra instituição. A moradora mantém o relacionamento, visitandoo semanalmente.

Recentemente adquiriu uma linha telefônica própria, para receber ligações pessoais, especialmente do namorado. Apesar de ser a última a se integrar ao grupo, tem demonstrado boa adaptação e um bom relacionamento com as colegas da casa. 
Relata que teve uma boa infância e adolescência, destacando o excelente relacionamento que tinha com a família. Carla narra sua história de vida de forma cronológica, separando-a em períodos: dos dez aos catorze anos, dos catorze aos dezessete e assim por diante. A narrativa só perde a seqüência cronológica a partir do momento da internação, quando a moradora perde as referências que a permitiriam situar-se no tempo. Durante o período de internação, só foi capaz de lembrarse de um número, o de anos que ficou na instituição: vinte e seis, número que, nas próprias palavras da moradora, representa "uma vida inteira".

O freqüente uso de números e datas na narrativa de vida de Carla representa, para ela, uma maneira bastante pessoal de organizar a sua história e reconstruir a sua identidade. Estabelecer a ordem dos acontecimentos e situá-los no tempo torna-se um importante meio de reconhecer-se como sujeito de sua própria história, permitindo-a localizar-se na sua narrativa.

A experiência de hospitalização é vista, por essa moradora, como uma etapa muito desagradável de sua vida. Sobre o período da internação, Carla não tem boas recordações: "Era muita maldade. Era uma coisa medieval, e acho que nem na Idade Média se agia com o ser humano como agiam com a gente. Era quarto forte, ficar sem banho, sem escovar dente, perdi meus dentes."

Após a mudança para a casa, Carla reelaborou todo o seu universo de significados e construiu, a seu modo, o novo espaço de moradia. A residência, para essa moradora, representou especialmente a conquista de um poder contratual que até então lhe era negado na instituição psiquiátrica: "É muito melhor ficar na residência terapêutica, na $R T$, do que no hospital psiquiátrico, é muito melhor. Eu saio sempre que preciso, para ir à rua, pegar dinheiro, marcar consulta. Faço muitas coisas".
De acordo com Delgado et al. (2000), o dispositivo residencial atua como um local intermediário, ou seja, um local de passagem, onde o sujeito recupera a sua autonomia. Nesse sentido, Carla concebe a residência como um local que servirá de travessia entre o hospital e a sociedade. É nesse espaço que a moradora poderá planejar e reconstruir a sua vida. Contudo, a conquista de autonomia é tão recente que Carla ainda precisará de algum tempo para reorganizar seu universo subjetivo de modo a construir sua liberdade e seu novo projeto individual de vida.

A liberdade, que até então era fornecida pelo hospital, passa, nesse novo contexto, a ser conquistada pelo morador. Somente com o tempo Carla poderá reorganizar seu universo subjetivo de modo a construir sua liberdade e seu novo projeto individual de vida.

Joice, 47 anos

Joice divide o quarto com Joana, com quem desenvolveu uma relação de proteção e cuidado. Joice orienta a companheira a cuidar de sua higiene pessoal e da arrumação do quarto. Em alguns momentos, torna-se arredia, mantendo-se na cama a maior parte do tempo. Relata ter passado por momentos muito difíceis em sua infância, enfatizando o momento em que ficou "abalada dos nervos". Atribui o surgimento de sua doença ao fato de ter trabalhado muito em casa, o que não permitiu que ela dispensasse tempo para outras atividades de seu próprio interesse. O abandono de seus desejos pessoais para dedicar-se a uma vida de intenso trabalho doméstico seria o fator desencadeante dos "problemas nos nervos", tal como o concebe a moradora.

Desse modo, Joice atribui a deflagração de sua doença e de sua inscrição como doente mental a um fator externo. Tal fator atua como um "marco", representando o momento a partir do qual a moradora não mais foi capaz de levar uma vida "normal". O abandono de 
seus desejos pessoais para dedicar-se a uma vida de intenso trabalho doméstico seria o fator desencadeante dos "problemas nos nervos".

Joice atribui à internação a necessidade de curar-se de sua "doença dos nervos", de sua "doideira". Em seu imaginário, a entrada no espaço hospitalar representaria a passagem para a cura, ou seja, o meio pelo qual ela poderia inserir-se novamente no mundo dos "normais".

A dificuldade para lembrar-se de datas e as lacunas entre a fala são recorrentes em sua narrativa. As longas pausas representam os momentos em que a moradora se esforça para lembrar do seu passado, como se buscasse reconstruí-lo através de informações perdidas, buscando preencher as lacunas deixadas pelos anos de institucionalização e cronificação.

Inserido no espaço manicomial, o indivíduo deixa de ser questionado sobre sua história. Esta é construída através dos dados que constam em sua papeleta, ou seja, as histórias de vida acabam psiquiatrizadas. A fala e o comportamento do sujeito são vistos através de sua patologia, de modo que o mesmo deixa de ser um sujeito singular e passa a ser um sujeito que sofre com uma determinada doença e possui sintomas específicos.

Joice demonstrou boa aceitação com a possibilidade de sair do hospital e mudar-se para uma residência terapêutica. Não demonstrou ansiedade ou quaisquer receios do novo espaço. Atribuiu sua segurança ao fato de já estar acostumada com tarefas domésticas.

O novo espaço de moradia permitiu que essa moradora se situasse subjetivamente em um novo universo de referências, tornando possível sua vinculação a um projeto de vida particular. Através da inserção no novo lar, Joice recuperou seu poder de decisão e direcionamento do seu cotidiano.
Joice finaliza seu depoimento com um apanhado geral de sua vida. Afirma que, apesar de seu sofrimento, sempre enfrentou todas as dificuldades com muita força e determinação. Através de um processo totalmente individual de reconstrução da identidade, vivencia novas possibilidades e produz novos significados em sua vida. Joice é determinada o bastante para enfrentar as dificuldades, e tem plena consciência disso. Em suas próprias palavras: "Sou cabocla, filha de índio e de sangue forte. Sou muito forte".

Joana, 58 anos

Joana permanece a maior parte do tempo deitada em sua cama, enrolada em um cobertor. Demonstrou-se solícita durante a entrevista, porém apresentou-se com discurso desconexo e de difícil compreensão. Essa moradora recebe cuidados mais intensos por parte de Joice, que a auxilia com uma postura extremamente maternal.

A dificuldade de verbalização e a incoerência no discurso ocasionaram diversas lacunas na transcrição da entrevista concedida por Joana. Sua narrativa é composta, principalmente, por fragmentos, frases soltas e palavras sem sentido. Não demonstrou capacidade de orientar-se adequadamente no tempo e no espaço, respondendo que possuía quatro anos e dezoito meses, ao ser questionada sobre sua idade.

A desorientação do discurso de Joana é nítida, especialmente nos momentos em que fala do filho que estaria em seu corpo. Companheiras da casa relataram, durante a realização de uma observação na residência, que Joana permaneceu internada por trinta e dois anos ininterruptos. Ao mencionar as "mães" com quem mora, cita o nome de três colegas da casa, que, em geral, são as que mais a auxiliam e orientam em suas atividades diárias.

Goffman (1961) aponta a perda de identidade que ocorre no interno de uma instituição total, 
perda essa que se dá através de numerosas experiências de "mortificação do eu". A instituição mantém o indivíduo afastado de seu mundo e acaba por destruir os laços que permitiriam que tais sujeitos se reintegrassem à suas famílias e à sociedade.

O contato com o hospital psiquiátrico passou a fazer parte das referências subjetivas de Joana, daí o desenvolvimento de sua relação de apego com a instituição, que permaneceu mesmo após a saída do espaço hospitalar. Tal afeto reside no fato de o hospital atuar como uma barreira protetora às adversidades do mundo externo.

Pacientes institucionalizados por um longo período acabam, em geral, perdendo a capacidade de lidar com simples atividades cotidianas, como realizar uma compra ou cuidar da própria higiene. Esse parece ser o caso de Joana, ainda muito marcada pelos longos anos de cronificação.

Joana diz gostar do hospital, não esboçando qualquer atitude negativa em relação ao seu tempo de hospitalização, ao contrário das demais colegas da casa. Demonstrou ter tido receio ao sair do hospital, relatando que lá tinha "a mãe". Contudo, ao ser questionada sobre a possibilidade de voltar para o hospital ou permanecer na casa, Joana responde enfaticamente que quer ficar onde está: " $A$ casa é boa, eu gosto de morar aqui...eu gosto do hospital, mas aqui eu tô gostando também, tá bom... Gosto daqui, é melhor, aqui é pra fazer casa. Aqui tem roupa, tem comida, tem quarto. Aqui é Deus."

A residência terapêutica permite uma reapropriação subjetiva muito rica, uma vez que o indivíduo readquire o seu poder de contratualidade e de controle sobre o uso de seu tempo. No entanto, sabe-se que esse processo é lento, especialmente em um caso como o de Joana. Sua vivência foi intensamente empobrecida pelo institucionalismo, fazendo com que essa moradora ainda mantenha suas referências manicomiais mesmo inserida no novo espaço de moradia.

\section{Reflexões conclusivas}

As narrativas e o cotidiano de moradores de residências terapêuticas estão permeados por uma subjetividade que emerge a partir das relações que estes estabelecem com seu novo meio social. Ao narrar sua trajetória pessoal, o sujeito organiza a sua experiência e evidencia o modo através do qual concebe o seu novo espaço de moradia.

Ao relatar sua história, o sujeito toma-se como "outro", através de um distanciamento do eu - narrador e eu - personagem. Esse processo permite ao indivíduo ordenar os acontecimentos e atribuir-lhes algum significado, projetando uma definição de si mesmo para o ouvinte.

Desse modo, a partir das narrativas aqui coletadas, tornou-se possível verificar como os moradores reconstruíram a sua identidade. A residência terapêutica atua como dispositivo facilitador para tal reconstrução, propiciando a criação de novos vínculos sociais através da proposta de plena integração do indivíduo à sociedade.

Inserido nesse novo cenário, o sujeito se engaja em um projeto individual de vida que construirá subjetivamente, através de seus desejos pessoais. A cidadania que lhe fora roubada pelo longo período de institucionalização é, enfim, recuperada. O morador readquire o seu poder contratual e sua autonomia, passando a ser sujeito de sua própria história.

Saraceno (1999) diferencia o "estar" no manicômio do "habitar" em uma casa. Na primeira condição, o sujeito se coloca de forma passiva perante a instituição, enquanto, no segundo caso, há a construção de uma nova realidade, na qual o sujeito atua de forma ativa
"A casa é boa, eu gosto de morar aqui... eu gosto do hospital, mas aqui eu tô gostando também, tá bom... Gosto daqui, é melhor, aqui é pra fazer casa. Aqui tem roupa, tem comida, tem quarto. Aqui é Deus." 
em seu novo espaço de moradia. E é justamente essa nova realidade que possibilitará, ao morador, construir novos laços com seu novo território.

É preciso atentar para o caráter residencial desse dispositivo de cuidado. A residência terapêutica é, acima de tudo, uma moradia, um lar que estimula a convivência social, a liberdade e a construção de novas possibilidades de vida, diferenciando-se, assim, dos demais serviços substitutos oferecidos atualmente.

Embora o Ministério da Saúde adote o termo serviço residencial terapêutico, as denominações "casas assistidas" e "lares abrigados" são, em geral, mais adotadas pelos defensores da reforma psiquiátrica. Tais nomenclaturas apontam não somente a proposta terapêutica do serviço, mas sim, o fato de ele constituir-se, prioritariamente, em um espaço de moradia e de trocas sociais.

Pitta (1996) ressalta que a residência incluída no território atua mais significativamente com o papel reabilitador se estiver articulada aos demais serviços da rede de saúde mental, como os CAPS, NAPS, oficinas terapêuticas, etc. A residência terapêutica, na cidade de Barbacena, faz parte de uma rede de serviços substitutos e está inserida no próprio território, para facilitar a integração dos moradores com a comunidade. Os moradores fazem acompanhamento médico e psicológico no CAPS e muitos freqüentam atividades de oficinas terapêuticas oferecidas na rede.

Apesar de a residência figurar como um serviço de caráter terapêutico, é preciso atentar para o fato de que esse dispositivo assume efetivamente a função de moradia, permitindo aos usuários a construção de um novo espaço subjetivo. Nesses locais, as histórias e vivências de cada um são permeadas pelas experiências com os colegas da casa, com os vizinhos e com toda uma nova gama de laços sociais que serão estabelecidos.
Reconhecer a especificidade do caráter de moradia da residência é crucial no sentido de evitar que a mesma se transforme em um "mini-hospício". Tais serviços não são clínicos por excelência, mas sim, locais em que novas experiências são vivenciadas a partir de uma apropriação do novo espaço e de uma relação de proximidade e pertencimento.

O modo pelo qual o indivíduo percebe e se apropria do novo espaço de moradia se dá através de uma construção estritamente individual, ou seja, de uma construção subjetiva. Sendo assim, cada morador constrói o significado do novo lar de forma distinta, embora estejam todos inseridos no mesmo espaço físico.

Através de construções subjetivas do cotidiano, os moradores recuperam a identidade social deteriorada pelos anos de confinamento no manicômio. A casa assume a função de abrigo, mas, ao mesmo tempo, atua como o espaço onde o sujeito resgata a sua cidadania e passa a ser sujeito ativo na reconstrução de sua identidade.

A conclusão deste trabalho não se esgota aqui. Ainda há muito o que extrair das falas destes e de tantos outros moradores que participam hoje do programa de residências terapêuticas. A conquista do novo lar, de novos laços sociais e de novas experiências no cotidiano representam processos extremamente complexos, especialmente por envolverem a subjetividade de cada usuário.

A residência terapêutica é um dispositivo assistencial de grande relevância para a atenção em saúde mental, uma vez que permite a emergência de novas e ricas experiências para o sujeito. Tais experiências continuarão a ser vivenciadas pelas moradoras dia após dia, o que indica que, no momento em que se encerra esta pesquisa, novas referências e possibilidades continuarão a ser construídas. 


\begin{tabular}{|c|c|}
\hline \multicolumn{2}{|c|}{$\begin{array}{r}\text { Vanessa Barreto Fassheber } \\
\text { Psicóloga, Especialista em Saúde Mental e Atenção Psicossocial (ENSP/FIOCRUZ) } \\
\text { Mestranda em Saúde Pública (ENSP/FIOCRUZ) }\end{array}$} \\
\hline Faculdade de Medi & $\begin{array}{r}\text { Carlos Eduardo Leal Vidal } \\
\text { cina de Barbacena Psiquiatra, Mestre em Saúde Pública } \\
\text { (Faculdade de Medicina de Barbacena). } \\
\text { Professor da Faculdade de Medicina de Barbacena }\end{array}$ \\
\hline Rua: Padre Tiago, 22 /501 & $\begin{array}{r}\text { Bairro: São Mateus CEP:36016-350 Juiz de Fora - MG } \\
\text { Tel.: (32)32134930/ (32)88188264 } \\
\text { E-mail: vafass@hotmail.com , celv@uol.com.br }\end{array}$ \\
\hline
\end{tabular}

AMARANTE, P. (coord). Loucos pela Vida: a Trajetória da Reforma Psiquiátrica no Brasil. Rio de Janeiro: Fiocruz, 1995.

BANDEIRA M, GELINAS D, LESAGE A. Desinstitucionalização: o Programa de Acompanhamento Intensivo na Comunidade. J. Bras. Psiq., 47(12), pp. 627-640.Rio de Janeiro, 1998.

BARBACENA. A Construção de uma Nova Lógica Assistencial e a Consolidação do Modelo da Reforma Psiquiátrica na Cidade das Rosas. Relatório de Gestão em Saúde Mental - período de jan. de 2001 a nov. 2004. Barbacena/MG, 2004. Não publicado.

BARBATO A, D. AVANZO B, ROCCA, G, AMATULLI, A, LAMPUGNANI, D. A Study of Long-stay Patients Resettled in the Community after the Closure of a Psychiatric Hospital in Italy. Psychiatric Services, pp. 67-70, 2004.

BIRMAN, J. A Cidadania Tresloucada. In: Amarante, P. Psiquiatria sem Hospício: Contribuições ao Estudo da Reforma Psiquiátrica. Rio de Janeiro: Relume-Dumará, 1992, pp. 71-90.

BRASIL. Ministério da Saúde. Legislação em Saúde Mental: 19902004. Ministério da Saúde, Secretaria-Executiva, Secretaria de Atenção à Saúde. 5ae ed. Ampliada. Brasília: Ministério da Saúde, 2004.

DELGADO, P.G. Perspectivas da Psiquiatria Pós-asilar no Brasil. In Tundis, S. \& Costa, N. (orgs) Cidadania e Loucura: Políticas de Saúde Mental no Brasil. Petrópolis: Vozes, 1994.

et al. A Autonomia do Sujeito Psicótico no Contexto da Reforma Psiquiátrica Brasileira . In: Psicologia: Ciência e Profissão, 2000, no 20, pp. 46-53.

DESVIAT, M. A Reforma Psiquiátrica. Rio de Janeiro: Fiocruz, 2002

FIRMINO, H. Nos Porões da Loucura. Rio de Janeiro: Codecri, 1982.
FURTADO J.P. Avaliação da Situação Atual dos Serviços Residenciais Terapêuticos Existentes no SUS. Março, 2005. Mimeo.

Núcleos de Apoio à Desinstitucionalização. Ministério da Saúde - Coordenação Nacional de Saúde Mental. Agosto, 2005. Mimeo.

GOFFMAN, E. Manicômios, Prisões e Conventos. São Paulo: Perspectiva, 1961.

LEFF J, TRIEMAN, N. Long-stay Patients Discharged from Psychiatric Hospitals. Br. J. Psychiatric, 176, pp.217-23, 2000.

MAGRO, J. Tradição da Loucura. Belo Horizonte: Coopemed, 1992. MINAYO, M. C. (orgs.). Pesquisa Social: Teoria, Método e Criatividade. Petrópolis: Vozes, 2000.

PITTA, A . O que É Reabilitação Psicossocial no Brasil Hoje? In: Pitta, A. Reabilitação Psicossocial no Brasil. São Paulo: Hucitec, 1996.

ROTHBARD,A.B, KUNO, E. SCHINNAR, A, HADLEY T, TURK R. Service Utilization and Cost of Community Care for Discharged State Hospital Patients: a 3-year Follow-up Study. Am. J. Psychiatric, 156, pp.920-27, 1999.

SARACENO, B. Libertando Identidades: da Reabilitação Psicossocial à Cidadania Possível. Rio de Janeiro: Instituto Franco Basaglia/Te Cora, 1999.

SPINK, M. J. (orgs.) Práticas Discursivas e Produção de Sentidos no Cotidiano: Aproximações Teóricas e Metodológicas. São Paulo: Cortez, 2000.

VIDAL, C.E.L., GONTIJO, E.C. \& BANDEIRA, M.B. Reforma Psiquiátrica e Serviços Residenciais Terapêuticos : a Experiência de Barbacena, MG. 2006. Não Publicado.
Referências 